\title{
Relación entre los niños de una comunidad indígena con la naturaleza y el Amazonas
}

\author{
Relationship between children from an \\ indigenous community with nature and the Amazon
}

\section{Relacionamento entre as crianças de uma comunidade indígena com a natureza e a Amazônia}

\author{
Ronald Fernando Quintana Arias ${ }^{* *}$ \\ Fecha de recepción: 1 de agosto 2016 \\ Fecha de evaluación: 5 de septiembre de 2016 \\ Fecha de aceptación: 5 de octubre de 2017 \\ Fecha de publicacion en linea: 1 de diciembre de 2017
}

DOI: http://dx.doi.org/10.18359/reds.3244

Cómo citar este artículo:

Quintana Arias, R.F. (2017). Relación entre los niños de una comunidad indígena con la naturaleza y el Amazonas. Revista Educación y Desarrollo Social, 11(2), 90-107. DOI: org/10/18359/reds.3244.

Artículo resultado del proyecto "Etnodesarrollo y medio ambiente: el conocimiento tradicional como estrategia para fometar el desarrollo sustentable y la identidad cultural de la comunidad indígena ticuna del Alto Amazonas, Macedonia", financiado por el Centro de Investigaciones y Desarrollo Científico de la Universidad Distrital Francisco Jose de Caldas.

** Licenciado en Biología, MSc en Desarrollo Sustentable y Gestión Ambiental, Universidad Distrital Francisco José de Caldas. Correo electrónico: ron902102004@gmail.com. 


\title{
Resumen
}

Entre 2009 y 2013 se buscó establecer las relaciones entre la naturaleza y niños, a través del análisis de nueve instrumentos obtenidos de la escuela Francisco de Orellana del resguardo indígena de Macedonia (Amazonas colombiano). La investigación llevó a la restructuración de los criterios de análisis planteados para la teoría de conglomerados de relevancia, a partir de la morfología simbólica y el reduccionismo ecológico. Esto evidenció un modelo mental indígena que no se centra en la palabra, sino en símbolos, actos concretos y ritos que hacen de la naturaleza y del Amazonas espacios indiferenciables. Finalmente, se recomienda dejar de equiparar la igualdad (bienestar merecido) con la diferencia (diversidad), ya que esto hace incompatible lo pluricultural y ve las distintas espiritualidades como no convergentes hacia valores interculturales que inciden directamente en la relación del ser humano con la naturaleza.

Palabras clave: Amazonas, conglomerados de relevancia, morfología simbólica, reduccionismo ecológico, símbolos.

\begin{abstract}
Between 2009 and 2013 there was a search to establish the relationship between nature and children, through analyzing nine instruments obtained from the school Francisco de Orellana at the Macedonia indigenous reserve (Colombian Amazon). The investigation led into the restructuration of the criteria of set data for the theory of related conglomerates, departing from symbol morphology and the ecological shortening. This proved an indigenous mental model that is not based on words but on symbols, true acts, and rituals that make of nature and the Amazon undistinguishable spaces. Finally, it's recommended not comparing equality (deserved wellness) with the difference (diversity), now that this makes the cultural diversity incompatible and sees the different religious ideas as no suitable towards intercultural values that affect the relationship of the humans with nature itself.
\end{abstract}

Keywords: Amazon, relative conglomerates, symbol morphology, ecological shortening, symbols.

\section{Resumo}

Entre 2009 e 2013, procurou-se estabelecer as relações entre a natureza e as crianças, através da análise de nove instrumentos obtidos da escola Francisco de Orellana da reserva indígena da Macedônia (Amazônia colombiana). A pesquisa levou à reestruturação dos critérios de análise propostos para a teoria do conglomerado de relevância, a partir da morfologia simbólica e do reducionismo ecológico. Isso demonstrou um modelo mental indígena que não se concentra na palavra, mas em símbolos, atos concretos e ritos que fazem da natureza e da Amazônia espaços não são divisíveis. Finalmente, recomenda-se que se pare de equiparar a igualdade (bem-estar merecido) com a diferença (diversidade), já que isso faz incompatível o multicultural e vê as diferentes espiritualidades como não convergentes em relação aos valores interculturais que afetam diretamente na relação do ser humano com a natureza.

Palavras-chave: Amazônia, conglomerado de relevância, morfologia simbólica, reducionismo ecológico, símbolos. 


\section{Ideas de naturaleza}

Las ideas de naturaleza, sus representaciones y contenidos constituyen marcos de interpretación que relacionan la cultura (procesos históricos y socioculturales específicos configurados en dinámicas sociales, económicas, históricas, políticas, educativas y religiosas —cosmológicas, cosmogónicas-) con las realidades mentales de las personas que la componen. De esta manera, las ideas de naturaleza están inmersas dentro de contextos y dinámicas que han generado una serie de negociaciones e intercambios culturales (Cloudsl, 1995; Cobern, 1996).

El planteamiento occidental de la idea de naturaleza en la Europa renacentista estuvo mediado por el capitalismo y por un dios sin objeto, muerto, eterno y estático, resultado de la configuración entre la ética y el intelecto. Asimismo, la Europa contemporánea se caracterizó por una sociedad industrial gobernada por un dios que cohíbe, único en todas sus partes y en conjunto, por lo que la idea de naturaleza formó parte de su proyecto en un proceso evolutivo e interminable. Por estas razones, se puede concluir que estos tres momentos históricos confluyen en la idea de naturaleza como proceso holístico orientado por Dios (Cloudsl, 1995).

Por otra parte, Oriente maneja una idea de naturaleza diferente a la de Occidente, lo que se refleja en el hecho de que la palabra "naturaleza" no tenga una traducción para el japonés. Este concepto se originó en Occidente debido al estudio del mundo natural (Glacken, 1967, 1996; Merchant, 1980), en el que la naturaleza se encuentra subordinada al hombre y, por consiguiente, este es su dueño:

[...] el hombre, en occidente, no era una parte común de la naturaleza [...] era una criatura especialmente privilegiada: la naturaleza estaba subordinada a él. Era el dueño del mundo natural, el cual estaba a su disposición para analizarla, examinarla y hacer uso de ella (Cobern, 1994. p. 80).

Por esa razón, la naturaleza se estudia, se infiere, se analiza, se examina y además se hace uso de ella (Murota, 1985).

A partir de lo anterior, Ogawa (1986) y Kawasaki (1990) hacen notar que la palabra shizen equivale a naturaleza, pero que su significado no es el mismo que el de Occidente, dado que la relación no es hacia el dominio, sino hacia la apreciación y contemplación de su belleza (en muchas ocasiones la naturaleza es su mejor compañera o amiga). Es de resaltar que este concepto ayuda en básica primaria a la enseñanza de las ciencias naturales (contemplación), mientras que en la secundaria cambia (método científico occidental) debido a las acciones de la "globalización", contraponiéndose a bases culturales que pueden llevar al rechazo del aprendizaje de la ciencia.

El aprendizaje no implica abandonar las ideas viejas por otras, ya que los alumnos tienen que usar el conocimiento escolar para todo, 
sino extender el repertorio de ideas sobre el mundo cultural, promoviendo múltiples representaciones mentales o esquemas conceptuales plurales que co-existen aunque son independientes [...] de modo que el alumno debería aprender a discriminar cuando son adecuadas y utilizarlas en contextos apropiados (Pozo et al., 2006, p. 9).

Desde otra perspectiva, estudios en África han demostrado que las raíces tradicionales en esta región son tan fuertes, que hacen difícil el tránsito a la visión de las ciencias occidentales. Por ejemplo, el filósofo africano Peter Bodunrin (1992) cita: "[...] admite la existencia en África de lo que se ha denominado el balance perfecto entre los sistemas metafísicos y los fenómenos del mundo razonable y absolutamente equilibrado, en armonía con estos sistemas" (p. 98).

Asimismo, existen visiones referidas al uso adecuado de recursos naturales y la proximidad con los dueños (espíritus o seres transdimensionales), que hacen posible una relación entre la naturaleza del cuerpo y del alma. De esta forma se generan seis tendencias: la primera ve al hombre, los animales y las plantas como objetos que no poseen vida, pero que tiene un propósito y un derecho a existir; la segunda es característica de las culturas judeocristiana e indígenas en las que se reciben dotes de uno o varios dioses (visión ética de lo sobrenatural). La tercera se basa en los postulados aristotélicos en que todos los com- ponentes de la naturaleza interactúan según su esencia concibiéndose como una totalidad; la cuarta ve al hombre como el guardián del planeta; la quinta ve al mundo como la evidencia de la existencia de Dios y, finalmente, la sexta considera al ser humano y a la naturaleza como un tejido cósmico unitario con una interdependencia simbiótica, en el que este es su guardián biológico y ecológico (Cloudsl, 1995).

En este orden de ideas, la naturaleza para los indígenas ha tenido un proceso de dinámicas que para el caso de Latinoamérica se ha caracterizado por la aculturización, deculturización e integración cultural (Ullán de la Rosa, 2000) en donde el contexto educativo (maloca, familia, ancianos, instituciones educativas) ha sido mediado por la religión (impuesta o tradicional) y por intereses económicos externos o internos.

La enseñanza, los saberes y competencias que pasan desde Occidente a otra sociedad o dentro de esta (hibridaciones, negociaciones, intercambios, traslaciones), son trascendentales en la identificación de la herencia cultural, y por ende en la comprensión y acciones sobre el mundo (ETSA y Gasché, 1996). Por consiguiente, la comprensión de aspectos sobre cosmovisión, epistemología, ontología y axiología comprometen los orígenes y dinámicas de la cultura en diferentes contextos (Molina, 2002) generando una asimilación de ciencia que nazca de los conocimientos cotidianos, de la sistematicidad de uso y de su significación cultural, lo que aumentará 
la resistencia al cambio cultural (Pozo y Gómez, 1998; Rivarosa, 1994).

Por consiguiente, todas las culturas han producido diferentes visiones del mundo (worldviews) (compuestas por el conjunto de creencias, consciente o inconscientemente sacadas de la naturaleza y de la realidad, que dan explicación al origen del conocimiento), las cuales enmarcan diferencias multiculturales significativas (Cobern, 1994 y 1996) como es el caso de África (Jegede, 1995, 1997), Japón (Kawasaki, 1990) y de indígenas americanos (ETSA y Gasché, 1996).

En este sentido, se aplicó una cartografía emocional cuyo análisis se fundamentó en los conglomerados de relevancias planteados por Molina $(2000 ; 2002)$ y Molina, Mojica y López (2006), lo que evidenció que la problemática de la enseñanza de las ciencias en contextos no occidentales no radica en hacerla más científica, sino culturalmente menos occidental: "Las habilidades cognitivas son socialmente transmitidas, socialmente constreñidas, nutridas y animadas" (Day, French y Hall, 1985, p. 40). Este proceso de enseñanza-aprendizaje debe entonces tener en cuenta tanto las variaciones subculturales como el contexto, ya que estos dos dan respuesta acerca de la comprensión-relación-causalidad del sujeto con el mundo natural (Abimbola, 1977; Ogunniyi, 1988).

\section{Conglomerados de relevancia}

Molina (2000) indica que un conglomerado de relevancias relaciona las ideas expresadas en el discurso con la importancia de las experiencias. Para ello se plantean dos categorías metodológicas: la narrativa y la de contenido semántico (Molina, 2002).

La categoría narrativa valora las referencias que se usan para expresar las ideas, lo que genera un acercamiento a la cultura (Molina, Mojica y López, 2006); esto se hace a través de descripciones expresadas en cartas, dibujos y diálogos, aunque en esta investigación se usan también fotografías tomadas por los estudiantes.

La categoría de contenido semántico busca identificar la idea principal y, como definen Pearson y Johnson (1978), establecer los conceptos principales y secundarios para ofrecer evidencia del desarrollo léxico básico o disponible de un individuo. En este sentido, a partir del análisis de las categorías se puede indicar un cambio entre la jerarquización de criterios (morales, conceptuales, actitudinales, emocionales y estéticos); simetrías entre lo moral, emocional y conceptual, o sencillamente un enfoque en uno solo de los aspectos mencionados anteriormente (Molina, 2008). Igualmente, Molina identifica pautas naturalistas, útiles, espaciales, ético-estético-emocionales y modelos de referencia tradicional y no tradicional (emblema nacional).

Es de resaltar que otro autor que ha seguido esta metodología ha añadido un criterio espiritual, pero contrario a lo que afirma Venegas (2012), para 
quien "la espiritualidad no es tangible, física, visible o definible con elementos del entorno" (p. 136), las comunidades indígenas han encontrado en lo que les rodea formas para generar canales de comunicación con los espíritus (Van der Hammen, 1991; Reichel, 1987; Quintana, 2009, 2012) a través de sus mitos (árboles sagrados, anacondas ancestrales), lo que hace que muchas culturas indígenas y no indígenas le asignen "dueños" a los lugares y plantas, con los cuales se tienen que establecer negociaciones de uso del recurso, o paso por el lugar (Quintana, 2013).

\section{Área de estudio}

La Institución Francisco de Orellana (Infradeo) está ubicada en la comunidad indígena de Macedonia, a 57 kilómetros de Leticia (Amazonas). Su origen se encuentra ligado a la llegada de indígenas a la zona desde 1930 (Quintana, 2009); en 1970 la interacción con pastores de la Iglesia Panamericana de Medellín, asociada a un fuerte invierno, llevó a la fundación de la comunidad y de Infradeo (Buitrago, 2007; Suárez, 2008; Quintana, 2011). Trece años después, a través del Instituto Colombiano de la Reforma Agraria (Incora), mediante la Resolución 060 del 21 de septiembre de 1983, Macedonia se constituyó en resguardo con un área de 3410 hectáreas propias, de las cuales 2460 , correspondientes a la isla de Mocagua Loreto, son compartidas con otras comunidades indígenas.
Desde el punto de vista sociocultural, el reporte del censo hecho en esta investigación junto con el Cabildo indígena de la comunidad determinó que Macedonia contaba en 2013 con 846 habi tantes, quienes pertenecen a siete grupos étnicos: ticunas (67\%), cocamas ( $25 \%$ ), yaguas $(0,4 \%)$, mestizos $(6,6 \%)$, huitotos $(7 \%)$, tanimucas $(0,5 \%)$ y boras $(0,4 \%)$.

En lo referente a su población y su economía, "[...] la pesca (84 \%), la caza (27 \%), las artesanías (88\%), la recolección de frutas y semillas del monte (51\%) y algunos trabajos en Leticia" (Riaño, 2003, pp.149-151), ocupan buena parte de las prácticas de subsistencia. "Estos datos reflejan la multi actividad de los habitantes de Macedonia que los acerca a una caracterización de bosquesinos" (Gasché y Echeverri, 2003, p. 1).

\section{Metodología}

Para el trabajo se logró la aprobación del Cabildo indígena y del Consejo de Ancianos, que especificaron las consideraciones éticas del estudio (consentimiento informado y autorización de uso de sus resultados). De esta manera, se contó con relatos de los abuelos sobre el origen mítico y la relación con la naturaleza, y se estableció que el proyecto buscaba determinar las relaciones entre la naturaleza y los niños a través del análisis de nueve instrumentos obtenidos en la escuela indígena Francisco de Orellana. 
Asimismo, se definió un enfoque de estudio de caso con una sola unidad de observación (Institución Francisco de Orellana), siendo esta una investigación etnográfica y etnometodológica que aplicaría técnicas de participación, teniendo herramientas de tipo etnográfico (consultas a manera de entrevistas y cartografía social y emocional) para obtener la información, lo que posibilitó un vínculo entre los actores sociales y el investigador y un intercambio de saberes (Fals Borda, 2000).

La investigación etnográfica tuvo un enfoque denominado por Arocha (1991) como "procesos intersubjetivos de consensualización", el cual al establecer relaciones trasversales mediante la confrontación entre lo que se hace, el beneficio de hacerlo y la importancia en la función que desempeña, lleva a una conciliación entre los enfoques etnográficos némicos (desde adentro o subjetiva) y néticos (desde afuera u objetiva).

Inicialmente en la ruta metodológica llevada a cabo en la escuela, se estipuló que se le brindaría a cada uno de los estudiantes una caja de plumones de 36 colores, lápiz, borrador y guías abiertas con dos preguntas, en las cuales explicaban y dibujaban lo que para ellos significaba la naturaleza y el río Amazonas en un contexto tradicional escolar. La actividad tuvo lugar 96 en la escuela, lo que la hizo ver como tediosa, por lo que al hablar con los estudiantes se "negoció" desarrollarla fuera de ella.
Debido a lo anterior, se tomó la iniciativa de salir del aula tratando de relacionar el "Shizen" planteado por Ogawa (1986) y Kawasaki (1990), en el que la contemplación y el encuentro directo fomentan la relación hombre-naturaleza, lo que sumado al contexto indígena significaría una aproximación a los "dueños, seres de otro mundo, lugares sagrados, animales míticos", pero se evidenció que para el contexto donde se encontraban, el papel y los colores afectaban directamente esa relación. Por ello se optó por cambiarlos por una cámara fotográfica, con la que los estudiantes en sus recorridos por la comunidad indígena pudieran plasmar lo que significaba la naturaleza y el río Amazonas; esto llevó a obtener registros fotográficos, escritos y videos en los que se analizan los sentimientos asociados a las imágenes relacionadas con los conceptos "Amazonas" y "naturaleza".

A partir de lo anterior, se habló de una cartografía emocional (fotografías y dibujos) que al sumársele el análisis de conglomerados de relevancias, permitió articular la ciencia y la belleza, ya que la ciencia no se vio como una forma de absorber la belleza al reducirla a números, tablas y mediciones, al reconocer algo de la belleza cultural que muchas veces la formación científica y los sentidos no logran percibir.

Por ende, al evidenciar cómo las creencias determinan la forma de comportamiento de los seres humanos en el espacio (lugares y no lugares) (Quintana, 2013), también es claro que estar sumido en una cultura diferente a la propia 
impide "ser", dado que es necesario adaptarse al entorno, lo que afecta el tipo de creencias y define la manera como se interactúa. En este sentido, las creencias les dicen a las personas cómo actuar y las actuaciones ante el mundo legitiman las creencias, por lo que estas se pondrán a prueba cuando el interés (social, económico, ambiental) se acerque al ideal buscado por el individuo en particular.

Debido a que el pensamiento lineal occidental reduce y descompone el total en pequeñas partes restándole importancia a la interacción entre ellas (Gavilán-Pinto, 2012), se integraron dos enfoques de relación hombre-naturaleza (morfología simbólica y reduccionismo ecológico) (Descola, 1986) al pensamiento en espiral característico de los pueblos indígenas. Para ello se articularon los criterios de análisis identificados por Molina (2000) de la siguiente manera:

1. Morfología simbólica: hace énfasis en el campo de la imaginación taxonómica y cosmológica, que da una aproximación más cercana a la cultura. Se debe prestar gran atención a la práctica en la naturaleza, lo que ayuda a descifrar el discurso codificado. Relación entre lo ético-estético-emocional y espiritual.

2. Reduccionismo ecológico: enfatiza en la utilización del recurso (la naturaleza sirve para comer) y cómo este se relaciona con:

- La función adaptativa.
- La concepción y el orden del mundo: se parte de la hipótesis de Van der Hammen (1991), en la que las referencias ecológicas ligan a los seres y no los segmentan, por lo que es posible unir conceptos como medio físico, flora, fauna, clasificaciones de los seres (sistemas, reinos, estructura celular, cadena alimenticia, entre otros), así como su relación con otros mundos (espiritual y occidental, entre otros).

- El marco histórico.

- Los modelos de referencia tradicional y no tradicional (emblema nacional).

- El consumo: diversidad de flora y fauna, comportamiento y alimentación de los animales y sus hábitos de caza.

\section{Resultados}

\section{Naturaleza sentida es naturaleza vivida}

Para empezar este recorrido se debe partir del contexto donde se establecen las explicaciones y nociones de la actividad, para ello se hablará de la cosmovisión asociada a la creación del mundo y de sus antepasados, para luego analizar la morfología simbólica y el reduccionismo ecológico, inseparables de un mundo espiritual en el marco de los conglomerados de relevancia.

\section{Creación del mundo}

El mundo se encontraba en la oscuridad, estaba cubierto por el "Wochine" 
cuyas grandes ramas no dejaban pasar la luz, por esta razón Yoi lanzó flechas desde su arco rompiendo algunas ramas, pero luego los huecos de este se volvían a cerrar. Por esta razón Yoi e Ipi se dieron cuenta que la única solución para que el mundo no estuviera más en tinieblas era tumbar el "Wochine", después de varios intentos tratando de cortar el árbol [...] deciden convocar la ayuda de los animales de la selva, entre ellos un oso perezoso que se quedó dormido a medio camino de su misión. Finalmente llegó una ardilla que [...] llevaba una mochila con polvo de ají y subió hasta donde el oso estaba y empezó a soplar en los ojos, boca, nariz, rabo y sobaco del animal. El oso adolorido empezó a rasguñar el árbol con sus garras [...] tumbó el "Wochine" que al caer permitió que la luz entrara a este mundo y cuya raíz generó el mar, y las ramas los ríos y las quebradas... (comunicación personal, abuelos de la comunidad ticuna, enero de 2009, Quintana, 2009, pp. 6 y 7).

\section{Origen del pueblo ticuna "Mangu- tangu aru Ngoechiga"}

Después de tumbar el "Wochine", Yoi toma su corazón "Umari", [...] decide convertirla en su novia [...] ,y esconderla en una flauta para que 98 su hermano no la encuentre [...] Finalmente Ipi [...] seduce a Umari, la convierte en su amante hasta que un día algo empezó a crecer dentro de
Umari [...] cuando Ipi intento meterla en la flauta se dio cuenta que no podía hacerlo y salió a esconderse con ella en la selva, Yoi [...] decide buscarlos en el bosque hasta que finalmente encuentra a Umari, al darse cuenta que estaba embarazada con el hijo de su hermano [...] Yoi [...] le dice a su hermano que [...] hay una forma para perdonarlo, lo único que debía hacer Ipi era bajar un fruto de "e" $y$ rayarla en el Evare, Ipi aceptó esta tarea y fue hasta el árbol a bajar su fruto [...] Finalmente llega a la cima y toma el fruto $[. .$.$] decide transformarse en otro$ fruto y dejarse caer, al llegar al suelo rápidamente toma el fruto y se dirige al río [... no se percató que al rayarlo se estaba rayando a sí mismo, hasta el punto que se rayó totalmente. Yoi al enterarse de lo que le sucedió a su hermano decide ir al Evare a obtener las partes del huito rayado por lo que se va a pescar con anzuelo utilizando como carnada pedazos de yuca, y es así como todos los peces que fueron capturados por Yoi se convirtieron en los TIKUNA (comunicación personal, abuelos de la comunidad ticuna de Macedonia, enero de 2009, Quintana, 2009, pp. 7 y 8 )

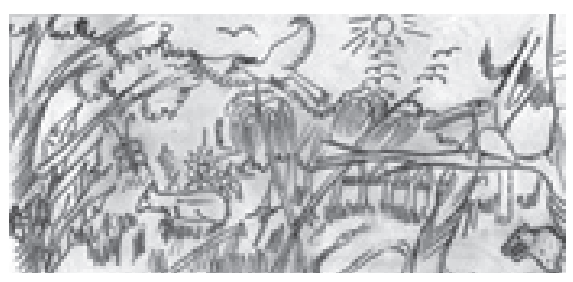

Figura 1. Naturaleza

Fuente: Lucas Santos (2013). 
Para el autor de la imagen 1, la naturaleza cobra importancia en el marco de la morfología simbólica al establecer una relación ético-estético-emocional: "La naturaleza es un lugar donde hay muchos seres vivos y en el cual se debe valorar lo que se encuentre en la naturaleza, no destruir los seres vivientes de la naturaleza, ni contaminar el ambiente... (entrevista personal a Lucas Santos, octubre de 2013). En este sentido, el estudiante refuerza la premisa con una postura de reduccionismo ecológico al considerar que "la contaminación destruye el oxígeno de la naturaleza y destruirla es destruir el Hombre" (entrevista personal a Lucas Santos, octubre de 2013).

Asimismo, el dibujo establece relaciones de función adaptativa, concepción y orden del mundo, que si se analizan tomando como referencia la cosmovisión indígena, indican un marco histórico que implica modelos de referencia tradicional y no tradicional, así como el comportamiento de una diversidad de animales y plantas.

[...] en la naturaleza hay mucha flora y fauna, muchos seres vivos que viven entre sí, como vemos acá una guara, una mariposa, acá hay una hormiga, el árbol es el del renaco aquí es un Martín pescador, los chulos y esa es un ave de tucán, el tigre y la culebra. La palma es Asai lo otros son pastos (entrevista personal a Lucas Santos, octubre de 2013).

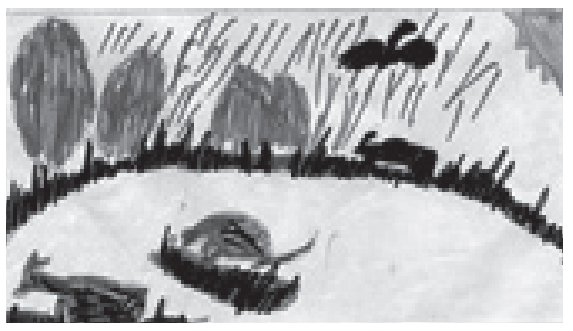

Figura 2. Naturaleza

Fuente: Yersi Saldaña y Fabricio Castro (2013).

Para los autores de la figura 2, la naturaleza cobra importancia en el marco de la morfología simbólica y el reduccionismo ecológico, al establecer una relación ético-estético-emocional y de uso del recurso simultáneamente:

[...] la naturaleza es importante porque con ella se puede respirar mejor para tener una vida alegre y estar feliz y para los animales son importantes la naturaleza y las plantas, las aguas, el aire ya que ellos también viven de la naturaleza... (entrevista personal a Yersi Saldaña y Fabricio Castro, octubre de 2013).

Asimismo, ellos establecen una categorización y orden que se relacionan directamente con el medio físico: "Encontramos el venado, el armadillo, un venadito, el chulo, el sol y los árboles [...] las lluvias son importantes [...]" (comunicación personal, Yersi Saldaña y Fabricio Castro, octubre de 2013).

Es de resaltar que para la autora de la figura 2 y la comunidad indígena, "Pedrito es el que nos cuida" (entrevista personal a niños de la comunidad ticuna, octubre 
de 2013). Al referirse a "Pedrito" hace alusión a una boa ${ }^{1}$ protectora que se encuentra cerca de la comunidad. Esta intervención del mundo de las aguas afecta el bienestar de la comunidad y los líderes espirituales indígenas o de la Misión Panamericana son los únicos que se pueden comunicar con ella.

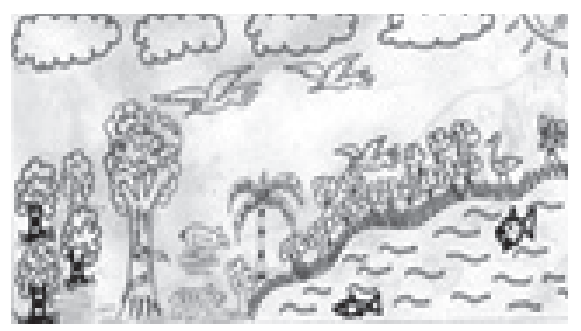

Figura 3. Naturaleza

Fuente: Liliana Suárez Arirama y Omaira Paredes Arimuya (2013).

La figura 3 tuvo como punto de partida la morfología simbólica: "La naturaleza es toda esencia y propiedad característica de cada ser, es decir que la naturaleza es lugar muy hermoso donde existen variedades de seres vivos [...]" (entrevista a Lilia Suárez Arirama y Omaira Paredes Arimuya).

En ella se expone una visión de reduccionismo ecológico cuando Liliana y Omaira hablan de un lugar en donde habita el hombre junto con animales y plantas, enmarcado en el equilibrio que lleva al bienestar:

1 Serpiente perteneciente a la familia Boidae. Su ancestro más grande se halló en Colombia y se le denominó Titanoboa cerrejonensis, lo que podría ser un indicio del origen de los mitos de las etnias ribereñas amazónicas.
[...] la naturaleza es lo que nosotros vivimos, cada persona la habita a ella. Este que se ve aquí es el amacizo que se encuentra a la orilla del río. Esta es una gaviota o [...] una paloma ceniza que se encuentra. Esta es Asai, eso es una Boruga, ese es un Chiguiro, esa es una Palometa. Lo que se encuentra acá es una Garza, este árbol que tiene una Serpiente es una Mantona [...] el sol se puso feliz porque todos están contentos. (entrevista a Lilia Suárez Arirama y Omaira Paredes Arimuya)

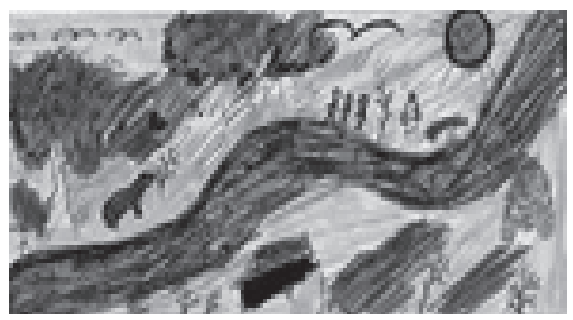

Figura 4. Naturaleza

Fuente: Bill Vásquez (2013).

Para el autor de la figura 4, la naturaleza tiene un fundamento espiritual que explica el origen y la organización del mundo, por lo que establece una relación trasversal entre la morfología simbólica y el reduccionismo ecológico, en este sentido

[...] La naturaleza es creada por un Hombre poderoso por su amor, por su inteligencia [...] sabiduría [...] Al principio el planeta tierra estaba en un gran desorden, luego un Hombre con toda su inteligencia organizó todo con su poder, y a él lo llamamos 
Dios por crear la naturaleza, de ahí nace y se origina todo aquel que nos rodea... (comunicación personal a Bill Vásquez, octubre de 2013).

Asimismo, el autor enfatiza una clasificación y uso de la naturaleza que sirve como indicativo para analizar las relaciones de los moradores con su entorno:

La naturaleza está compuesta por los animales, plantas, aves, nosotros los humanos, los insectos, los peces, las aguas en que vivimos [... ] árboles medicinales, maderables, plantas, pastos [...] insectos [...] esta es una casa y estos son gente [...] estas son casas de los indios, una es hoja la otra es de zinc [...] la gente vive ahí porque siempre ha sido así (comunicación personal, Bill Vásquez, octubre de 2013).

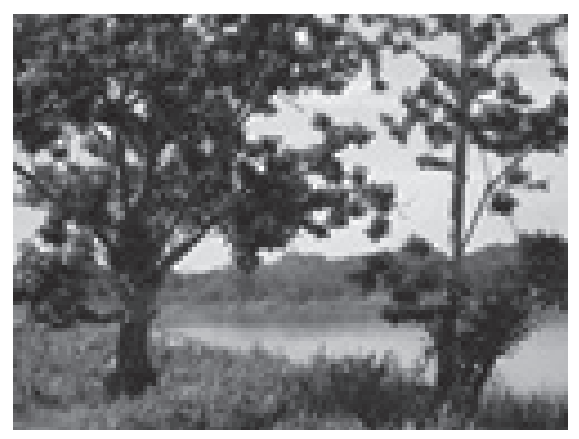

Fotografía 1. Naturaleza

Fuente: Carolina Núñez (2013).

Para la Carolina Núñez, autora de la fotografía 1, hablar de naturaleza y del Amazonas es hablar de lo mismo. Ella dice que en la fotografía "se ve todo lo que es de la naturaleza, toda clase de plantas, de frutas [... ] se ve todo". Su explicación muestra una idea ecológica radical sobre el uso que le da el hombre a la naturaleza, ya que lo que enmarca en la fotografía es el río Amazonas y al frente la isla de Loreto Mocagua, donde las mujeres de la comunidad tienen sus chagras. $^{2}$

Pero haré énfasis en esa frase de la autora: "se ve todo", lo que exige un análisis de morfología simbólica. En este sentido, se enmarca una posición de la naturaleza expresada por niños de la comunidad y analizada por Quintana (2011):

[...] el río crece y se convierte en el hogar de la boa [...] el agua se asocia con el mundo espiritual; y al ser las profundidades de este elemento un límite de este mundo cerrado, se inicia el campo de lo desconocido [...] un cielo azul con nubes al igual que el río [...] enmarca el control que el Hombre tiene sobre el mundo (agua, tierra, clima) [...] y una visión dinámica del paisaje (p. 111).

De esta manera, hablar sobre la naturaleza y el río (Amazonas) es hablar de un mundo natural y sobrenatural, en el que se establecen relaciones de vida y ciclos geoestacionales, siendo más evidente la relación de las lluvias, la diversidad de especies acuáticas y la disponibilidad de productos en diferentes épocas.

$2 \quad$ La chagra es el lugar donde los indígenas plantan sus cultivos y en el que además plasman su cosmovisión. Es el espacio de la mujer, ella es la dueña, aunque el hombre colabora con algunas tareas. La disposición y variedad de los cultivos hacen que sea ambientalmente muy sostenible. 


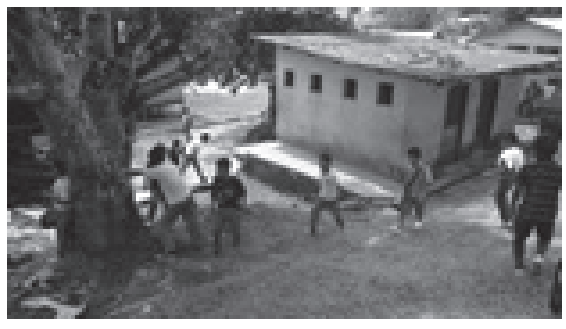

Fotografía 2. Naturaleza

Fuente: Nelsy Sánchez (2013).

Nelsy Sánchez, autora de la fotografía 2 , ve una morfología simbólica que al generar un sentido de responsabilidad por la familia y por el entorno crea modelos de referencia tradicional y no tradicional (reduccionismo ecológico), que se deben a un orden del mundo en el cual la responsabilidad recae en el hombre, y definen que formamos parte de él y por ello debemos cuidarlo:

La naturaleza es belleza, la naturaleza es algo real que Dios nos ha dado, los niños están tocando el árbol porque somos la naturaleza, los árboles y todo lo que hay ahí a nuestro alrededor, los niños son el futuro del país, del Amazonas son el futuro de su familia, de sus padres (comunicación personal, Nelsy Sánchez, octubre de 2013).

El análisis del concepto entremezcla la morfología simbólica y un reduccionismo ecológico con una lógica de paisaje real indígena que "amplía al privilegiar un centro vital sobre el límite, condensando el tiempo con una visión de 'territorio-hogar'" (espacio humanizado) (Quintana, 2013, p 112); el cual depen- de tanto de nosotros, como nosotros dependemos de él.

\section{Amazonas sentido es Amazonas vivido}

Para hacer el análisis del Amazonas se debe contemplar el mundo de las aguas y la relación que este elemento tiene con su origen como se evidencia en los mitos expuestos anteriormente.

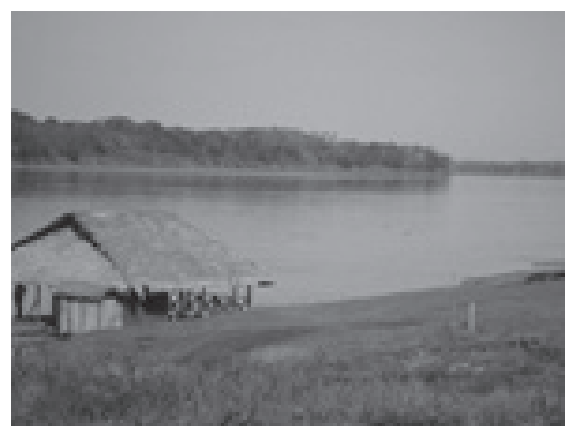

Fotografía 3. Río Amazonas

Fuente: Nara Arimuya (2013).

A partir del análisis de las entrevistas a las mujeres de la comunidad, se destaca una relación de temor con el río: "No se debe entrar al río cuando se tiene el periodo [...] es malo, el río tiene muchos animales y espíritus antiguos [...] que huelen eso y se llevan a las mujeres para hacerlas suyas..." (comunicación personal, mujeres de la comunidad ticuna, octubre de 2013). Es de resaltar que esta tendencia de relación con el río es algo supraétnico, por lo que todas las mujeres sin importar la etnia tiene esa misma concepción. 
Para el autor de la fotografía 3, se establece una relación entre la morfología simbólica y el reduccionismo ecológico directamente con una concepción de orden del mundo y criterios morales:

El río es vida, de ahí viene todo lo que nosotros tenemos, algunos abuelos dicen que de ahí se originó todo y que debemos portarnos bien con el río porque tiene muchas cosas [...] castiga gente si no te portas bien con los demás... (comunicación personal, Nara Arimuya, octubre de 2013).

A partir de lo anterior se puede decir que hablar de un mundo de las aguas adquiere mucha importancia para la etnia, dado que su origen tradicional indica que fueron pescados por Yoi; hecho mítico que estableció relaciones sobre lo que es la vida correcta y la incorrecta a través del manejo del cuerpo y de la moral. Quintana (2009) lo ratifica al decir que en la comunidad se tiene la creencia de que una persona buena, generosa, respetuosa, que sabe escuchar, aprender y enseñar no será propensa a contraer enfermedades, a no ser que otros se las hayan enviado a través de la magia.

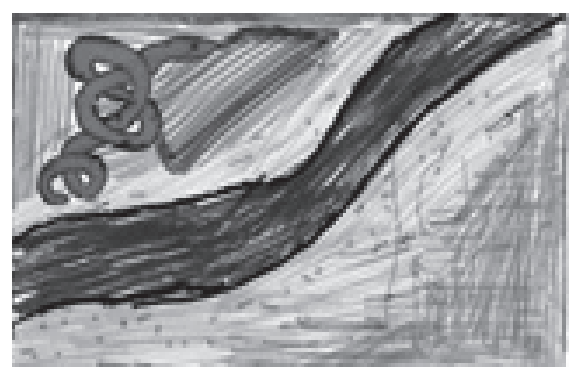

Figura 5. Río Amazonas

Fuente: Bill Vásquez (2013).
Al entrevistar al autor del dibujo de la figura 5 se resalta un enfoque de reduccionismo ecológico al exponer un lugar y sus componentes:

El Amazonas es el segundo río más grande del mundo, por lo cual está ubicado en Sudamérica, se destaca por sus grandes extensiones de plantas, animales, aves y es el río más largo. Está compuesto por arena, pozos, animales, pastos, lo café de acá son chagras... (comunicación personal, Bill Vásquez, octubre de 2013).

Lo anterior pone en evidencia una relegación de la morfología simbólica en la explicación, pero una revalorización de esta con el dibujo. Como se puede apreciar, una serpiente no descrita por el autor ocupa una gran parte del dibujo, con lo que muestra un fenómeno de contexto como lo expresó el autor en otra entrevista: "No se puede hablar de esas cosas en el colegio [...] los libros no dicen eso que hablan los abuelos [...]" (comunicación personal, Bill Vásquez, octubre de 2013).

Eso significa que la academia, al no reconocer contextos culturales distintos, homogeneiza e influye en la relación que establece con la morfología simbólica tradicional (leer análisis de la imagen 6), conflicto que llevará a largo plazo a una pérdida de creencias y posiblemente a un servilismo cultural. ${ }^{3}$

Término que hace alusión a acciones de las personas de diferentes etnias para adquirir beneficios económicos a través de la comercialización de una cultura, en la que no necesariamente creen, pero que les representa una fuente de ingresos. 


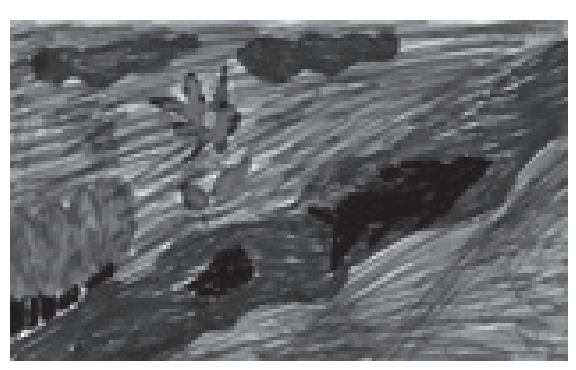

Figura 6. Río Amazonas

Fuente: Yelsil Saldaña y Fabricio Castro (2013).

Al observar el dibujo lo primero que sobresale es el azul, por lo que se deduce que hablar del Amazonas es hablar del río; un río que se enriquece con las lluvias (su color y el de las nubes es el mismo). Es de resaltar que las zonas donde debería estar la gente son azules, lo que es una manera de evidenciar las dinámicas de inundaciones que tienen las áreas donde viven las comunidades amazónicas.

Las explicaciones muestran el reduccionismo ecológico que establece relaciones ecosistémicas entre el hombre y los servicios ambientales del río, lo que origina un sentido de bienestar para los estudiantes:

Para nosotros el Amazonas es importante para los animales porque cuando ellos salen a tomar agua a las piedras pueden divertirse por los ríos [... el Amazonas es importante para las personas porque en el Amazonas hay mucho pescado... (comunicación personal, Yelsil Saldaña y Fabricio

Asimismo, al empezar la descripción de su dibujo enmarca una categorización

de animales y plantas propia del reduccionismo ecológico:

Esto es un pirarocu y aquí es una boa, pero hay más serpientes [...] estos pedacitos son árboles y toda esa agua, esta es una flor, es una victoria regia, estos son puros árboles de amacizo, esto las hojitas de la victoria regia y estas las nubes [...] El Hombre no se ve pero siempre ha estado ahí (comunicación personal, Yelsil Saldaña y Fabricio Castro, octubre de 2013).

\section{Conclusiones}

- La ruta metodológica evidenció un modelo mental indígena no centrado en la palabra sino en símbolos, actos concretos y ritos; la experiencia vivencial, más que la racionalista, une sentimientos y emociones. Entre la morfología simbólica y el reduccionismo ecológico se entrevé un todo que es más que la suma de sus partes, por lo que al definir un concepto con el sentimiento asociado, se genera una relación más profunda entre el lugar donde se obtiene tanto la cultura occidental como la indígena, de tal suerte que la escuela mediadora de estos conocimientos lleva aprendizajes híbridos que revalorizan el saber tradicional.

- Para los jóvenes participantes en la actividad, hablar de la naturaleza es hablar del Amazonas, son espacios indiferenciables cuyo origen mítico los convierte en uno, y esta relación 
se debe tener en cuenta para fomentar una clase de biología que fomente la cultura tradicional y propicie un intercambio saberes que genere un verdadero conocimiento escolar.

- El trabajo con las cámaras tuvo ventajas sobre el que hicieron en papel, pues al brindarles a los estudiantes instrumentos tecnológicos que no tenían, se produjo un sentimiento de felicidad en el grupo y eso facilitó el desarrollo de las actividades. Ello pone en evidencia una tecnología que fomenta pertenencia, lo que legitima los planteamientos de García-Canclini (1990) en cuanto a la generación de una glocalización en el marco de la globalización.

- Para un análisis de ideas de naturaleza en contextos indígenas es necesario salir de la forma tradicional como se conciben los conceptos de las ciencias en la enseñanza occidental, y ampliarlos a "conceptos de realidad", lo que hace que el contexto sea el determinante para la forma como se deben analizar las interpretaciones hechas por los jóvenes dentro de una comunidad indígena.

- Resulta paradójico evaluar competencias de biología en una prueba nacional, dado que no se reconocen los saberes indígenas como conocimientos científicos, históricos o filosóficos. Lo anterior representa un reto para los profesores de etnociencias, quienes deben visibilizar mucho más ante el Estado colombiano la problemática que trae una globalización homogeneizadora de saberes, que fomentan una nueva forma de neocolonialismo.

\section{Recomendaciones}

Es necesario dejar de equiparar la igualdad (bienestar merecido) con la diferencia (diversidad), ya que esto hace incompatible lo pluricultural y ve las distintas espiritualidades como no convergentes hacia valores interculturales que inciden directamente en la relación del hombre y la naturaleza.

\section{Referencias}

Abimbola, W. (1977). Ifa: an exposition of Ifa literary corpus. Ibadan (Nigeria): Oxford University Press.

Arocha, J. (1991). Autocontrol valorativo vs. recetas etnográficas. Bogotá: Universidad Nacional de Colombia.

Bodunrin, P. (1992). Philosophy in Africa: The Challenge of Relevance and Commitment. En H. Nagl-Docekal y F. M. Wimmer (Eds.), Postcolonial African Philosophy (pp. 15-35). Munich y Viena: Oldenbourg.

Buitrago, I. (2007). Trayectorias vitales memoria familiar y memoria histórica en Macedonia: una comunidad indígena del trapecio amazónico colombiano. (Tesis de Maestría). Leticia, Universidad Nacional de Colombia.

Cloudsl, T. (1995). Ideas of Nature in the European Imagination. History of European Ideas, 20, 333-340.

Cobern, W. (1994). Alternative Constructions of Science and Science Education. Education Research, 27-30. 
Cobern, W. (1996). Constructivism and NonWestern Science Education Research. International Journal of Science Education, 4(3), 287-302.

Day, J., French, L. y Hall, L. (1985). Social Influences on Cognitive Development. En D. Forrest-Pressley, G. McKinnon y T. W. (Eds.), Metacognition, Cognition and Human Performance, vol. 1 (pp. 33-56). New York: Academic Press.

Descola, P. (1986). La Nature Domesique: Simbolismeet praxis dans lécologie des achuar. París: Maison des Sciences de l'Homme.

ETSA y Gashe, J. (1996). Los alcances de la noción de "cultura" en la educación intercultural. Exploración de un ejemplo: sociedad y cultura bora. EnJ. E. Godenzzi, Educación e Interculturalidad en los Andes y la Amazonía (pp. 187-285). Cusco-Perú: Centro de Estudios Regionales y Andinos Bartolomé de las Casas.

Fals Borda, O. (2000). El territorio como construcción social. Revista Foro (38), 45-51.

García-Canclini, N. (1990). Culturas híbridas. Buenos Aires: Paidós.

Gavilán-Pinto, V. (2012). El pensamiento en espiral: el paradigma de los pueblos indígenas. Santiago de Chile: Ebook Producción.

Gasché, J. y Echeverri, J. (2003). Sociodiversidad bosquesina: un acercamiento desde el enfoque de una sociología comparativa. Proyecto IIAP-IMANI [Inédito].

Glacken, C. (1996). Huellas en la playa de Rodas. Naturaleza y cultura en el pensamiento occidental desde la Antigüedad 106 hasta finales del siglo XVIII. Barcelona: Ediciones del Serbal.

Jegede, O. (1995). Collateral learning and the eco-cultural paradigm in science and mathematics education in Africa. Studies in Science Education, 25, 97-137. Jegede, O. (1997). School science and the development of scientific culture: A review of contemporary science education in Africa. International Journal of Science Education, 19, 1-20.

Kawasaki, K. (1990). A Hidden Conflict Between Western and Traditional Concepts of Nature. The Bulletin of School of Education Okayama University, 83, 203-214.

Merchant, C. (1980). The death of nature: women, ecology, and the scientific revolution. San Francisco: Harper \& Row.

Molina, A. (2000). Conhecimento, Cultura e Escola: Um estudo de suas Inter-relações a partir das idéias dos alunos (8-12 anos) sobre os espinhos dos cactos. São Paulo. Faculdade de Educação, Universidade de São Paulo, Brasil.

Molina, A. (2002). Conglomerado de relevancias y formación científica de niños, niñas y jóvenes. Revista Científica, (4), 187-200.

Molina, A. (2008). La investigación al alcance de su mano. Bogotá: Fondo de Publicaciones.

Molina, A., Mojica, L. y López, D. (2006). Ideas de los niños y niñas sobre la naturaleza: estudio comparado. Revista Científica, (7), 41-62.

Murota, Y. (1985). Culture and the environment in Japan. Environmental Management, 9, 105-111.

Ogawa, M. (1986). Toward a new rationale for science education in a non-western society. European Journal of Science Education, 8, 113-119. 
Ogunniyi, M. (1988). Adapting western science to African traditional culture. International Journal of Science Education, 10, 1-10.

Pearson, P. y Johnson, D. (1978). Teaching reading comprehension. New York: Macmillian.

Pozo, J., y Gómez, M. (1998). Aprender y enseñar ciencias: Del conocimiento cotidiano al conocimiento científico. Madrid: Morata.

Pozo, J., Scheuer, N., Pérez, M., De la Cruz, M. et al. (2006). Nuevas formas de pensar la enseñanza y el aprendizaje. Barcelona: GRAO.

Quintana, R. (2009). El "verdadero" guardián del oro verde. Estudio etnobotánico en la comunidad indígena de Macedonia. Tesis de grado para optar por el título de Licenciado en Biología. Universidad Distrital Francisco José de Caldas.

Quintana, R. (2011). Sombras invisibles: Las representaciones de niños y niñas miraña en una comunidad tikuna. Revista Chilena de Antropología Visual (17), 92-111.

Quintana, R. (2012). Estudio de plantas medicinales usadas en la comunidad indígena tikuna del Alto Amazonas, Macedonia. Nova: Publicación Científica en Ciencias Biomédicas, 10(18), 179-191.

Quintana, R. (2013). Reconfiguración simbolica del territorio. Los "no lugares". Revista Chilena de Antropología Visual, 40-59.

Quintana, R. (2014). Etnodesarrollo y medio ambiente: el conocimiento tradicional como estrategia para fomentar el desarrollo sustentable y la identidad cultural de la comunidad indígena tikuna del Alto Amazonas, Macedonia. Bogotá: Tesis de grado para optar por el título de Magister en Desarrollo Sustentable y Gestión Ambiental. Universidad Distrital Francisco José de Caldas.

Reichel, E. (1987). Astronomía yukunamatapí. En Etnoastronomías americanas. Bogotá: Universidad Nacional.

Riaño, E. (2003). Organizando su espacio, construyendo su territorio: transformaciones de los asentamientos TIKUNA en la ribera del Amazonas colombiano. Leticia: Universidad Nacional de Colombia, IMANI, Unibiblos.

Rivarosa, A. (1994). El diálogo entre las ciencias en la historia de las ciencias: una clave para el aprendizaje en la escuela. En González, A. Aprender el currículum o aprender a pensar: un falso dilema. Buenos Aires: Troquel.

Suárez, G. (2008). Etnografía de la comunidad de Macedonia. Leticia: Institución Educativa Francisco de Orellana, comunidad indígena de Macedonia.

Ullán de la Rosa, J. 2000. Los indios Tikuna del alto amazonas ante los procesos actuales de cambio cultural y globalización. Revista Española de Antropología Americana, (30), 291-336.

Van der Hammen, M. (1991). El manejo del mundo, naturaleza y sociedad entre los yukuna de la Amazonia colombiana. Bogotá: Tropembos.

Venegas, A. (2012). Criterios de análisis en la interpretación de las ideas de naturaleza con los conglomerado de relevancias. 